\title{
Body size and mortality in women: a 29 year follow up of 12000 pregnant women in northern Finland
}

Esa Läärä, Paula Rantakallio

\begin{abstract}
Study objective - To examine the association between body height, body mass index (BMI), and mortality in fertile women of childbearing age.
\end{abstract}

Design - A prospective cohort study with a 29 year mortality follow up.

Setting and participants - A cohort of women $(n=11$ 997) expected to deliver during 1966 in two northern provinces of Finland. Data on height and prepregnancy weight, collected with those on sociodemographic characteristics and smoking by questionnaire at the third trimester, were provided by $91 \%$ of the participants. Follow up for mortality using national registries was from delivery until the end of 1994.

Main results - Height had a ' $U$ ' shaped association with total mortality over the whole follow up time. In women who were shorter than average, the death rate from cardiovascular diseases was increased and in taller women this was true for tumours. Compared with the women of 'normal weight' (BMI 21 to $<25 \mathrm{~kg} / \mathrm{m}^{2}$ ), the obese subjects (BMI at least 29) did not have increased mortality during the first 20 years, but had a relative risk of 1.7 during the final nine years of follow up, primarily as a result of cardiovascular diseases. The lean women (BMI < 21) experienced a similar rate overall, but moderately overweight women (BMI 25 to $<29$ ) had a consistently lower mortality than women of normal weight.

Conclusions - Among fertile women of childbearing age, both the short and tall seem to have an increased total mortality compared with those of average body height, resulting from opposite trends in major causes of death. Obesity is associated with raised long term total mortality. (F Epidemiol Community Health 1996;50:408-414)

Department of Public Health Science and General Practice, Faculty of Medicine University of Oulu, FIN-90220, Finland. ELäärä

PRantakallio

Correspondence to: Mr E Läärä

Accepted for publication February 1996
The relation between body height, body mass, and mortality has been a topic of extensive epidemiological research. Most studies are restricted to white, middle aged or older, middle class men in western countries. There are fewer data on women of different ages and social and ethnic groups. The results of the few reports in young and middle aged females, as well as those, more numerous, in males vary. The interpretation of many studies is shadowed by methodological shortcomings in them, such as not accounting for smoking habits. ${ }^{1}$ This study aimed to shed more light on the association between body height, body mass, and mortality from certain major groups of causes of death in fertile women of childbearing age by following up a cohort of women in northern Finland who were pregnant in 1966 and from whom a large amount of baseline data was collected during pregnancy, including height and prepregnancy weight.

\section{Methods}

STUDY POPULATION

The target population consisted of all pregnant women living in the two northern provinces (Oulu and Lapland) of Finland whose estimated date of delivery fell in 1966. Details of the study design are described elsewhere. Briefly, the women were recruited to the cohort when they visited their municipal maternity health centre on their 7 th or 8 th month of pregnancy. The number of recruited women who met these criteria and subsequently gave birth was $12055 ; 13$ of them had completed two pregnancies, the expected dates both falling in the target period. The number of deliveries in this cohort was $96 \%$ of the number of births recorded in the two provinces during $1966 .^{2}$ Those cohort members for whom the personal identification number was found later on $(n=11997)$ were considered eligible for the mortality study.

\section{MEASUREMENT}

At the recruitment visit the women completed a structured questionnaire. It contained items on demographic and socioeconomic characteristics (date of birth, marital status, municipality of residence, occupation of the subject and her husband, working and living conditions at the time of pregnancy, size of the family); educational level; smoking habits of the subject (did she smoke and how many cigarettes daily during the 12 months before pregnancy, and did she change her smoking habits during this pregnancy, how, and at which month); height $(\mathrm{cm})$; and pre-pregnancy weight $(\mathrm{kg})$ of the subject and an obstetric history.

For statistical analyses, height (in $\mathrm{cm}$ ) was divided into five categories: (1) less than 154, (2) $154-157$, (3) $158-162$, (4) $163-166$, and (5) 167 or more. Quetelet's body mass index (BMI) was calculated as the pre-pregnancy weight $(\mathrm{kg})$ divided by height $(\mathrm{m})$ squared. The 
Table 1 Distribution (no (\%)) of some baseline characteristics in the northern Finland cohort of pregnant women of 1966, and the distribution (\%) of height and body mass index (BMI) in the categories of these characteristics

\begin{tabular}{|c|c|c|c|c|c|c|c|c|c|c|c|}
\hline \multirow[b]{2}{*}{ Characteristic } & \multirow[b]{2}{*}{ No of women (\%) } & \multicolumn{4}{|c|}{ Distribution (\%) of height $(\mathrm{cm})$} & \multicolumn{5}{|c|}{ Distribution (\%) of $B M I\left(\mathrm{~kg} / \mathrm{m}^{2}\right)$} & \multirow[b]{2}{*}{ Total } \\
\hline & & $<158$ & $158-162$ & $\geqslant 163$ & Missing & $<21$ & $21-<25$ & $25-<29$ & $\geqslant 29$ & Missing & \\
\hline \multicolumn{12}{|l|}{ Age (y) } \\
\hline $14-24$ & $4372(36)$ & 23 & 33 & 39 & 5 & 36 & 47 & 7 & 1 & 8 & 100 \\
\hline $25-29$ & $3359(28)$ & 26 & 35 & 35 & 4 & 26 & 51 & 14 & 3 & 7 & 100 \\
\hline $30-34$ & 2047 (17) & 32 & 33 & 29 & 4 & 14 & 49 & 20 & 7 & 9 & 100 \\
\hline $35-49$ & 2219 (19) & 37 & 33 & 23 & 7 & 8 & 38 & 26 & 14 & 14 & 100 \\
\hline \multicolumn{12}{|l|}{ Years of schooling } \\
\hline$<5$ & $1083(9)$ & 38 & 22 & 30 & 9 & 10 & 36 & 24 & 14 & 16 & 100 \\
\hline $5-8$ & $8801(73)$ & 29 & 33 & 32 & 6 & 24 & 47 & 15 & 5 & 10 & 100 \\
\hline$>8$ & $2113(18)$ & 20 & 35 & 44 & 1 & 32 & 52 & 11 & 2 & 3 & 100 \\
\hline \multicolumn{12}{|c|}{ Socioeconomic status } \\
\hline I and II (high) & $2736(23)$ & 23 & 35 & 39 & 3 & 26 & 51 & 15 & 3 & 5 & 100 \\
\hline III & $3858(32)$ & 26 & 35 & 34 & 5 & 30 & 47 & 13 & 4 & 7 & 100 \\
\hline IV (low) & $3222(27)$ & 30 & 31 & 31 & 8 & 23 & 44 & 13 & 5 & 14 & 100 \\
\hline Farmer & $2181(18)$ & 32 & 34 & 28 & 6 & 13 & 46 & 20 & 10 & 11 & 100 \\
\hline \multicolumn{12}{|c|}{$\begin{array}{c}\text { Smoking during year } \\
\text { before pregnancy }\end{array}$} \\
\hline No & $9414(78)$ & 28 & 34 & 32 & 5 & 22 & 47 & 16 & 6 & 9 & 100 \\
\hline Yes & $2583(22)$ & 26 & 32 & 37 & 5 & 32 & 45 & 11 & 3 & 9 & 100 \\
\hline $\begin{array}{l}\text { Total } \\
\text { (No) }\end{array}$ & $11997(100)$ & $\begin{array}{l}28 \\
(3331)\end{array}$ & $\begin{array}{l}34 \\
(4039)\end{array}$ & $\begin{array}{l}33 \\
(3983)\end{array}$ & $\begin{array}{l}5 \\
(644)\end{array}$ & $\begin{array}{l}24 \\
(2909)\end{array}$ & $\begin{array}{l}47 \\
(5625)\end{array}$ & $\begin{array}{l}15 \\
(1766)\end{array}$ & $\begin{array}{l}5 \\
(604)\end{array}$ & $\begin{array}{l}9 \\
(1093)\end{array}$ & $\begin{array}{l}100 \\
(11997)\end{array}$ \\
\hline
\end{tabular}

BMI values $\left(\mathrm{kg} / \mathrm{m}^{2}\right)$ were divided into four categories: (1) lean: BMI < 21, (2) normal weight: BMI 21 to < 25, (3) overweight: BMI 25 to $<29$, and (4) obese: BMI at least 29. No direct validation for the self reported prepregnancy weight was possible. The credibility of the recalled weight was assessed indirectly by comparing it to the weight measured and recorded at the first visit to the maternity health centre. It was found that for most subjects the difference between these weight values was within normal variation of weight cycling during pregnancy.

Smoking before pregnancy was dichotomised as (1) 'yes' (at least one cigarette per day during the year before pregnancy; missing values included in this class) versus (2) 'no'. Educational level was treated as a three level factor: (1) less than 5 years, (2) 5 to 8 years (missing values were pooled into this class), and (3) more than 8 years of schooling. Socioeconomic status of the subject was classified according to the occupational group of the husband, or of the subject herself if single, into following categories: (1) I and II (including professionals), (2) III (including skilled workers), (3) IV (unskilled workers; missing values included), and (4) farmers.

MORTALITY FOLLOW UP

Since 1967 each citizen in Finland has had a unique personal identification number; this was obtained from the Population Register Centre of Finland for all but $58(0.5 \%)$ members of the cohort. These numbers were utilised in linking the records of the cohort with the files of the national registry of causes of deaths, maintained by Statistics Finland and covering the entire population resident in the country. From these files we obtained the date and the underlying cause of death of the members of the cohort registered to have died between 1966 and 1994. The causes of death, according to the 9th revision of the International Classification of Diseases (ICD), were divided into four groups: (1) cardiovascular diseases, ICD 390-459, (2) tumours, ICD 140-208, of which breast cancer, ICD 174, was taken separately, (3) injury and violence, ICD 800-999, E800-999, and (4) all other causes. Another source of dates of deaths (not containing causes) was the files of the national Population Register Centre with which the records of the cohort were also linked.

Follow up for mortality started at the date of delivery and stopped at the date of death, recorded date of emigration, or January 1, 1995, whichever was the earliest. The latter two were the possible censoring times. A date of emigration occurring by the end of 1993 was found for 614 women through record linkage with the Population Register Centre. Some undercoverage of emigrations has generally been observed in this register, especially for the period of the emigration boom in the late $60 \mathrm{~s}$ and early $70 \mathrm{~s}$, mainly directed to Sweden. Hence, 416 cohort members had a date of emigration occurring by the end of 1980 recorded in the population register. However, from other sources of information it was found that 609 children ( $5 \%$ ) born to these women in 1966 were resident abroad in 1980 when the 14 year follow up study of the child cohort was conducted. ${ }^{3}$ To assess the sensitivity of our results to the undercoverage of migrations we also performed all person-year and mortality calculations under the following assumption. For those women who had no recorded emigration date or death by 1980 , but who had children living abroad in 1980, the date of emigration was assigned to be the beginning of 1972 . The results were essentially similar to those obtained by adopting the emigration dates as recorded by the population register.

\section{STATISTICAL METHODS}

Numbers of deaths, person-years at risk, and mortality rates were calculated in categories of height and BMI before pregnancy as defined above, jointly stratified by age at delivery (14-24, 25-29, 30-34, 35-49 years) calendar period ('early': 1966-73, 'intermediate': 197485, and 'late': 1986-94), and smoking during the year before pregnancy (yes, no). Standardised rates were calculated for the height and 
BMI groups using the distribution by age and smoking of the whole cohort at delivery time as the source of standard weights. ${ }^{4}$ Test statistics and $p$ values for linear trend of the rates over the categories of height and BMI adjusting for age and smoking were calculated by the principle of internal standardisation. ${ }^{4}$ The Cox proportional hazards regression model was applied to estimate the relative risks of mortality for other categories of BMI versus $21-<25 \mathrm{~kg} / \mathrm{m}^{2}$ and those of height versus $157-$ $161 \mathrm{~cm} .{ }^{4}$ The potential confounders (age at delivery, smoking, educational level, and socioeconomic status) were adjusted for by including these in the model. The Cox model was fitted for both the whole follow up period and in the three subperiods defined above, using the program $B M D P 2 L$.

\section{Results}

Follow up for mortality was possible for 11997 eligible subjects with a known personal identification number. Altogether $95 \%$ of them provided data on their height and $91 \%$ on pre-pregnancy weight too. The distribution of the chosen potential confounders by height and $\mathrm{BMI}$ is presented in table 1 , pooling the two shortest and two tallest categories of height. Height was positively associated with education, socioeconomic status, and smoking and negatively with age. Body mass was positively associated with age and negatively with smoking and years of schooling. There was a slight negative correlation between height and BMI (data not shown).

During the follow up, 622 women died in 326700 person-years. Altogether 614 members of the cohort were censored at their registered emigration date by the end of 1993 .
Seven out of every 10 deaths were either from cardiovascular causes (199 deaths) or from tumours (241). For $15(2 \%)$ women with a date of death recorded in the population register no record was found from the registry of causes of death. These women were citizens of Finland, but were resident abroad, mostly in Sweden, when they died and the information on the death had been sent to Finland by the officials of the country of residence.

When adjusting for the effects of age and smoking by direct standardisation, the mortality rates were smallest in the median height category of $158-162 \mathrm{~cm}$, increasing in both low and high levels of height in all subperiods of follow up. The relative risks of the short and the tall women were greater in the first eight years than the subsequent 21 years of follow up (table 2). This $U$ shaped pattern was composed of opposite trends in the mortality rates from major groups of causes.

Over the whole 29 years, the short women had the highest and tall women the lowest mortality from cardiovascular diseases and from injury and violence (table 2). Mortality from all tumours was highest among the tal women compared with the other height groups. Breast cancer (51 deaths), constituting about one fifth of the total tumour mortality, also indicated an increased risk for the tallest women, but the precision of the comparison was poor. Mortality from the remaining causes seemed to have a $U$ shaped pattern in relation to height, but due to small number of cases this observation was still consistent with the assumption of no association. In particular, we could not evaluate the association of height with mortality from respiratory diseases, because there were only 15 deaths from these causes.

Table 2 Numbers of deaths, person years at risk (in thousands), and standardised* mortality rates (per 100000 years) by height during different follow up periods in the northern Finland cohort of pregnant women of 1966 . (P value for trend in rates over the height categories in parentheses)

\begin{tabular}{|c|c|c|c|c|c|c|c|}
\hline \multirow[b]{2}{*}{ Follow up period } & \multicolumn{6}{|c|}{ Height category $(\mathrm{cm})$} & \multirow[b]{2}{*}{ Total } \\
\hline & -153 & $154-157$ & $158-162$ & $163-166$ & $167-$ & Missing & \\
\hline \multicolumn{8}{|l|}{$1966-73$} \\
\hline All deaths & 13 & 16 & 13 & 14 & 8 & 1 & 65 \\
\hline Person-years & 9.1 & 15.8 & 30.2 & 19.5 & 10.2 & 4.8 & 89.5 \\
\hline Rate $(p=0.31)$ & 139 & 92 & 45 & 76 & 110 & 15 & 73 \\
\hline \multicolumn{8}{|l|}{$1974-85$} \\
\hline All deaths & 24 & 41 & 58 & 41 & 22 & 13 & 199 \\
\hline Person-years & 13.9 & 24.2 & 46.7 & 30.1 & 15.8 & 7.2 & 137.8 \\
\hline Rate $(p=0.95)$ & 160 & 159 & 128 & 152 & 148 & 159 & 144 \\
\hline \multicolumn{8}{|l|}{$1986-94$} \\
\hline All deaths & 44 & 65 & 110 & 70 & 39 & 30 & 358 \\
\hline Person-years & 9.9 & 17.3 & 33.8 & 21.6 & 11.4 & 5.1 & 99.2 \\
\hline Rate $(p=0.90)$ & 401 & 349 & 337 & 350 & 390 & 504 & 361 \\
\hline \multicolumn{8}{|l|}{$1966-94$} \\
\hline All deaths & 81 & 122 & 181 & 125 & 69 & 44 & 622 \\
\hline Person-years & 33.0 & 57.3 & 110.7 & 71.2 & 37.4 & 17.1 & 326.7 \\
\hline Rate $(p=0.71)$ & 225 & 197 & 168 & 191 & 240 & 222 & 190 \\
\hline \multicolumn{8}{|l|}{ Vascular diseases } \\
\hline Deaths & 31 & 40 & 64 & 40 & 16 & 13 & 204 \\
\hline Rate $(p=0.29)$ & 80 & 62 & 60 & 65 & 50 & 62 & 62 \\
\hline \multicolumn{8}{|l|}{ Tumours } \\
\hline Deaths & 25 & 48 & 75 & 44 & 34 & 15 & 241 \\
\hline Rate $(\mathrm{p}=0.19)$ & 68 & 76 & 69 & 68 & 104 & 75 & 74 \\
\hline \multicolumn{8}{|c|}{ Injury and violence } \\
\hline Deaths & 15 & 15 & 26 & 26 & 8 & 4 & 94 \\
\hline Rate $(p=0.27)$ & 47 & 27 & 24 & 37 & 21 & 27 & 29 \\
\hline \multicolumn{8}{|l|}{ Other causes } \\
\hline Deaths & 8 & 12 & 14 & 14 & 10 & 10 & 68 \\
\hline Rate $(p=0.62)$ & 25 & 19 & 13 & 20 & 33 & 48 & 21 \\
\hline
\end{tabular}

* Standardised for the joint distribution by age and smoking of the whole cohort at baseline. 
Table 3 Numbers of deaths, person-years at risk (in thousands), and standardised* mortality rates (per 100000 years) by body mass index (BMI) during different follow up periods in the northern Finland cohort of pregnant women of 1966 ( $P$ value for trend in rates over the BMI categories in parentheses)

\begin{tabular}{|c|c|c|c|c|c|c|}
\hline \multirow[b]{2}{*}{ Follow up period } & \multicolumn{5}{|c|}{ BMI category $\left(\mathrm{kg} / \mathrm{m}^{2}\right)$} & \multirow[b]{2}{*}{ Total } \\
\hline & $<21$ & $21-<25$ & $25-<29$ & $29-$ & Missing & \\
\hline \multicolumn{7}{|l|}{$1966-73$} \\
\hline All deaths & 16 & 32 & 6 & 5 & 6 & 65 \\
\hline Person-years & 21.7 & 42.0 & 13.2 & 4.5 & 8.1 & 89.6 \\
\hline Rate $(p=0.08)$ & 106 & 80 & 34 & 123 & 57 & 73 \\
\hline \multicolumn{7}{|l|}{$1974-85$} \\
\hline All deaths & 38 & 84 & 31 & 20 & 26 & 199 \\
\hline Person-years & 33.3 & 64.8 & 20.5 & 6.9 & 12.3 & 137.8 \\
\hline Rate $(p=0.80)$ & 151 & 136 & 110 & 120 & 191 & 144 \\
\hline \multicolumn{7}{|l|}{$1986-94$} \\
\hline All deaths & 61 & 149 & 53 & 41 & 54 & 358 \\
\hline Person-years & 24.0 & 46.8 & 14.9 & 4.9 & 8.7 & 99.2 \\
\hline Rate $(p=0.03)$ & 300 & 337 & 308 & 575 & 529 & 361 \\
\hline \multicolumn{7}{|l|}{$1966-94$} \\
\hline All deaths & 115 & 265 & 90 & 66 & 86 & 622 \\
\hline Person-years & 79.0 & 153.6 & 48.6 & 16.3 & 29.2 & 326.7 \\
\hline Rate $(p=0.24)$ & 183 & 181 & 149 & 258 & 254 & 190 \\
\hline \multicolumn{7}{|l|}{ Vascular diseases } \\
\hline Deaths & 31 & 70 & 34 & 37 & 32 & 204 \\
\hline Rate $(\mathrm{p}<0.001)$ & 65 & 49 & 55 & 125 & 88 & 62 \\
\hline \multicolumn{7}{|l|}{ Tumours } \\
\hline Deaths & 40 & 116 & 36 & 21 & 28 & 241 \\
\hline Rate $(p=0.82)$ & 62 & 79 & 56 & 60 & 82 & 74 \\
\hline \multicolumn{7}{|l|}{ Injury and violence } \\
\hline Deaths & 28 & 42 & 10 & 5 & 9 & 94 \\
\hline Rate $(p=0.43)$ & 30 & 28 & 19 & 63 & 31 & 29 \\
\hline \multicolumn{7}{|l|}{ Other causes } \\
\hline Deaths & 12 & 31 & 8 & 3 & 14 & 68 \\
\hline Rate $(p=0.62)$ & 22 & 21 & 16 & 10 & 43 & 21 \\
\hline
\end{tabular}

* Standardised for the joint distribution by age and smoking of the whole cohort at baseline.

In the first eight years and the intermediate nine to 20 years from the beginning of the follow up, the observed mortality differences between the body mass groups were mostly well within random variation (table 3 ); those who were moderately overweight (BMI 25 to $<29 \mathrm{~kg} / \mathrm{m}^{2}$ ), however, clearly had a lower mortality than women in the 'normal' range (BMI 21 to <25). In the last nine years of follow up, starting individually 19 to 20 years after the beginning, mortality among the lean women was lower than that in the groups of normal weight and moderate overweight, the latter two being approximately similar, but the death rate of the obese women was about two times higher than in these two other groups.

Over the whole 29 years, the obese women had highest rate of death from vascular diseases. The mortality in the lean women compared with those of normal weight or moderate overweight was slightly increased from vascular diseases and decreased from tumours; these contrasts, however, were well within random variation. In the first eight years cancer mortality among the lean women was higher, but not remarkably so, compared with all other BMI classes (data not shown). The overweight subjects had a lower mortality than the women of normal weight in all major groups of causes other than vascular diseases, but again each of these contrasts could be attributed to chance.

Essentially similar results were obtained by fitting the Cox model to the data on total mortality in the different periods, with age, smoking, educational level, and socioeconomic status as covariates (table 4 ). When the analysis was restricted to the non-smoking women only, the mortality patterns in the three periods were not very different from that in the whole cohort, and the results for the smoking women were statistically consistent with those for nonsmoking subjects but much less precise (not shown).

Table 4 Estimated relative mortality rates (with the 95\% confidence intervals in parentheses) from all causes of death in different categories of body height and body mass index (BMI) based on fitting the Cox proportional hazards model in different follow up periods, including age, smoking, education, and socioeconomic status as covariates, in the northern Finland cohort of pregnant women of 1966

\begin{tabular}{|c|c|c|c|c|}
\hline & \multicolumn{3}{|l|}{ Subperiod } & \multirow[b]{2}{*}{ Whole period 1966-94 } \\
\hline & $1966-73$ & $1974-85$ & $1986-94$ & \\
\hline \multicolumn{5}{|l|}{ Height (cm) } \\
\hline-153 & $2.54(1.11,5.83)$ & $1.21(0.73,2.01)$ & $1.15(0.79,1.66)$ & $1.27(0.96,1.68)$ \\
\hline 154-157 & $2.14(1.00,4.59)$ & $1.39(0.92,2.10)$ & $1.06(0.77,1.45)$ & $1.24(0.98,1.57)$ \\
\hline $158-162$ & 1 & 1 & 1 & 1 \\
\hline $163-166$ & $1.93(0.89,4.17)$ & $1.28(0.84,1.94)$ & $1.03(0.75,1.41)$ & $1.17(0.92,1.48)$ \\
\hline $\begin{array}{c}167- \\
\text { BMI }\left(\mathrm{kg} / \mathrm{m}^{2}\right)\end{array}$ & $2.02(0.79,5.14)$ & $1.36(0.81,2.28)$ & $1.29(0.89,1.87)$ & $1.36(1.02,1.82)$ \\
\hline $\begin{array}{l}<21 \\
<211\end{array}$ & $1.34(0.72,2.47)$ & $1.11(0.75,1.65)$ & $0.93(0.68,1.26)$ & $1.03(0.82,1.29)$ \\
\hline $21-<25$ & 1 & (4) & 1 & $\begin{array}{l}1.03(0.82,1.29) \\
1\end{array}$ \\
\hline $25-<29$ & $0.42(0.17,1.01)$ & $0.86(0.57,1.31)$ & $0.88(0.68,1.26)$ & $0.81(0.64,1.04)$ \\
\hline $29-$ & $0.77(0.29,2.03)$ & $1.30(0.78,2.16)$ & $1.71(1.19,2.46)$ & $1.45(1.09,1.92)$ \\
\hline
\end{tabular}




\section{Discussion}

Our cohort was drawn from a geographically well defined source population, being virtually homogenous with regard to ethnic background, language, and religion, but covering a wide spectrum of different socioeconomic strata. The distribution of pregnant women with regard to these characteristics was, for obvious reasons, somewhat different from that in the general female population of that age range. In particular, infertile women were not included. It has been observed that body mass has a $U$ shaped relation with the risk of infertility. ${ }^{67}$ Therefore, the spectrum of BMI values represented in this study population was probably narrower than it would have been in the general population of the same age range.

Self reported pre-pregnancy values of height and weight were obtained from $91 \%$ subjects. Some overestimation of height and underestimation of the true weight and BMI can be expected. ${ }^{8}{ }^{9}$ This misclassification is likely to be non-differential in relation to our outcome variable, and hence it probably tended to dilute to some extent the estimates of relative risk for example, between the obese and the normal weight subjects. It is also unlikely that we would have obtained qualitatively different results if data on BMI had been available for all subjects.

The potential confounding due to cigarette smoking was at least partly controlled for in our analyses. Self report on whether or not one was regularly smoking during the year before pregnancy is, of course, not an entirely satisfactory indicator of the usual long term smoking habits before and after the index pregnancy. Quantification of tobacco exposure was omitted, because there were so few women who reported smoking more than 10 cigarettes per day. Even so, this binary smoking variable turned out to be a strong determinant of mortality in this cohort, because the overall adjusted relative risk estimate associated with it was about two. ${ }^{10}$ We therefore think that adjustment based on this indicator removed an essential part of confounding due to smoking and is far better than not accounting for smoking at all, which is a problem in interpreting the results of many other studies on body size and mortality. ${ }^{1}$

Other predictors of mortality, like educational level and socioeconomic status, were also adjusted for. It is obvious that some residual confounding due to both smoking habits and social background still remained after these, relatively crude, adjustments. We attempted to control for a possible confounding by some latent serious diseases which could have decreased the pre-pregnancy weight from its normal level in some women, at least partially, in two ways. Firstly, the members of the study population were healthy enough for conception and delivery. Secondly, the first seven to eight years of follow up were analysed separately from the remaining 21 years.

There was no essential loss to follow up, as the dates and causes of death in residents of Finland during this period were completely covered by the registry of causes of death Deaths occurring in subjects who have emigrated are commonly not recorded in this registry. However, other check ups indicated that both the emigration rate was overall rather small and the coverage of emigrations by the Population Register Centre moderately good, and hence losses due to emigration apparently produced a negligible bias in the results.

We observed a $U$ shaped relationship between body height and all cause mortality in the different subperiods of follow up. This pattern has previously been found, for example in a 17 year follow up of a Norwegian cohort, among women who were initially younger than 50 years but not in women at least 50 years, nor in men. ${ }^{11}$ In addition, in other studies on cohorts with an older age distribution than ours, the mortality rate of the tall subjects has not usually been greater, but rather, smaller, than those of average height, whereas short individuals generally seem to have a higher risk of death. ${ }^{12}{ }^{13}$ The discrepancies can be partly explained by the different impacts of various causes of deaths in populations with different age distributions. Our cohort was rather young, so the proportional contribution of vascular diseases was smaller and that of tumours much larger than in older populations. Hence, the $U$ shaped curve was a result of a net effect of the opposite mortality trends of these two major groups of causes. Among tall women, the low mortality from vascular diseases could not compensate for the relatively high death rate from tumours.

In cardiovascular diseases, the inverse association between height and mortality has been observed by many others, both in women and in men, and has also been found in studies on the incidence of cardiovascular events. ${ }^{14} 15$ This has often been interpreted as reflecting differences in living conditions in childhood. Individuals who are shorter than average are presumed to have been brought up in poorer circumstances than the taller ones. It is suggested that these differences lead to a gradient of cardiovascular risk factors, unfavourable for the short and favourable for the tall. ${ }^{15}$ The evidence for this hypothesis is not, however, entirely convincing. ${ }^{13}$ It has also been suggested that an existing disease may have shortened body height, and therefore the excess mortality from, for example, vascular diseases among short individuals, may be partly explained by this 'shrinkage'." 13 Our data are too sparse to provide adequate evidence either for or against this hypothesis.

In contrast to cardiovascular diseases, cancer mortality was higher among the tall women than in the other height groups, in line with some previous observations as well as certain theoretical considerations supported by some animal experiments. ${ }^{13}$ However, a major part of the observed associations of height with mortality from tumours, as well as any other cause group, could well be due to residual confounding by inadequately measured socioeconomic factors. ${ }^{13}$ The numbers of deaths from injury and violence as well as from other causes were also too small for any precise 
conclusions. Of particular interest among these would be the respiratory diseases, for which the inverse effect of height has been one of the strongest among individual causes of death in some studies. ${ }^{113}$

Obesity is an ever topical health concern in the western countries, particularly in Finland. ${ }^{16-18}$ There is ample epidemiological evidence of the various health hazards associated with overweight, ${ }^{19}$ but there are still many unanswered questions and controversies, especially concerning the appropriate management of obesity. ${ }^{2021}$

The review by Manson et $a l^{1}$ covered only one long term prospective study on body weight and all cause mortality in young and middle aged women in which smoking was taken into account, ${ }^{22}$ but no consistent relationship between BMI and cumulative mortality over a 25 year period was found in this Dutch cohort of only 1500 women. Since then new studies have been published on women of these ages. The $U$ shaped pattern between BMI and total mortality during the early (first seven to eight years) and the intermediate (the next 12 years) periods of follow up observed in our study was also found in a larger cohort of Finnish women, ${ }^{23}$ followed up for 14 years, and in a large Norwegian population. ${ }^{11}$ In the latter, however, control for smoking was totally lacking. Stevens et al reported a similar pattern in 25 to 28 year mortality rates for white women, but no clear pattern for black women emerged. ${ }^{24}$ The sizes of these subcohorts were very small, so the differences between black and white women, as well as those between these cohorts and ours, are well within chance variation. Our results in the first 20 years are also consistent with the BMI-mortality curve observed over comparable follow up periods in the larger cohorts of young Dutch, ${ }^{25}$ young and middle aged Finnish men, ${ }^{26}$ middle aged British men, ${ }^{27}$ and Harvard alumni. ${ }^{28}$

One peculiar feature in our results compared with all others is that the nadir of the BMI-mortality curve in all sub-periods and among both non-smokers and smokers occurred in the category of moderate overweight (BMI 25 to $<29 \mathrm{~kg} / \mathrm{m}^{2}$ ), not in the BMI group commonly considered 'normal' or optimal (21 to $<25 \mathrm{~kg} / \mathrm{m}^{2}$ ). This pattern was observed over the whole period and in each major cause of death group other than vascular diseases. Even though the contrast between these two BMI groups in the first eight year period was almost 'significant' by common statistical jargon, we still hesitate to conclude that the optimal BMI is greater in northern Finnish women than elsewhere.

The relative risk of the lean women compared with those of normal weight in the first two subperiods was high, but not significantly so. As noted above, this observation is in line with many others, but there are studies in which the leanest group of the non-smoking, and otherwise apparently healthy, subcohort did not experience increased mortality. ${ }^{29} 30$

In the last nine years, which started 20 years from the beginning of follow up, the mortality rate among the obese women was accelerating faster than in any other BMI group. This change in the BMI-mortality pattern after 20 years is consistent with the results from the Harvard alumni cohort, ${ }^{28}$ as well as other studies in which a strong direct association between relative body weight and adverse outcome emerged only after a long-term follow up. ${ }^{19}$ The major component in the high total mortality among the obese subjects was cardiovascular mortality.

A major restriction in all the studies referred to above, and including ours, is that weight was assessed only at the beginning of follow up. Several studies indicate that substantial weight loss, weight gain, or cycling of weight in general predict increased risk of death compared with stable weight or modest weight change at most levels of baseline weight. ${ }^{31}$ It is difficult, however, in these studies to separate the consequences of voluntary and involuntary weight loss from each other. Recently, the distribution of body fat has received increasing attention, too. It appears, for example, that the simple waist/hip ratio measurement, not performed in our study, is a stronger independent predictor of mortality than BMI. ${ }^{24}$

Nevertheless, even a single measurement of body weight at one point in time still conveys important information on mortality risk. ${ }^{28}$ In our cohort of fertile-aged Finnish women leanness was associated with a slightly raised mortality during the subsequent 20 years, while obesity began to predict increased risk of death after 20 years had passed since the assessment of weight. On the other hand, the optimal body height in respect of total mortality risk appears to be the average stature.

We thank Mr Markku Koiranen and Mr Arto Muhli for skilful work in data management and statistical computations. This study was supported by a grant from the Academy of Finland.

1 Manson JE, Stampfer MJ, Hennekens $\mathrm{CH}$, Willett WC. Body weight and longevity: a reassessment. $f A M A$ 1987;257:353-8.

2 Rantakallio P. Groups at risk in low birth weight infants and perinatal mortality. Acta Paed Scand 1969; Supp 193:1-71

3 Rantakallio P, Myhrman A, Koiranen M. Juveline offenders, with special reference to sex differences. Soc Psychiatry Psychiatr Epidemiol 1995;30:113-20.

4 Breslow NE, Day NE. Statistical methods in cancer research. Volume II - The design and analysis of cohort studies. Lyon: IARC Scientific Publication No 82. Lyon: International AARC Scientific Publication No 82. L

5 Dixon WJ ed. BMDP statistical software manual. Berkeley CA: University of California Press, 1990.

6 Grodstein F, Goldman MB, Cramer DW. Body mass index and ovulatory infertility. Epidemiology 1994;5:247-50.

7 Rich-Evans JW, Goldman MB, Willett WC, et al. Adolescent body mass index and infertility caused by ovulatory disorder. Am 7 Obstet Gynecol 1994;171:171-7.

8 Stewart AW, Jackson RT, Ford MA, et al. Underestimation of relative weight by use of self-reported height and weight. of relative weight by use of self-re

9 Nieto-Garcia FJ, Bush TL, Keyl PM. Body mass definitions Nieto-Garcia FJ, Bush TL, Keyl PM. Body mass definitions
of obesity: Sensitivity and specificty using self-reported of obesity: Sensitivity and specificty using self
weight and height. Epidemiology 1990;1:146-52.

10 Rantakallio P, Läärä E, Koiranen M. A 28 year follow up of mortality among women who smoked during pregnancy. $B M \mathcal{F}$ 1995;311:477-80.

11 Waaler HT. Height, weight and mortality: The Norwegian experience. Acta Med Scand 1984; Suppl 679;1-56.

12 Nyström Peck AM, Vågerö DH. Adult body height, self perceived health and mortality in the Swedish population. $f$ Epidemiol Community Health 1989;43:380-4.

13 Leon D, Smith GD, Shipley M, Strachan D. Adult height and mortality in London: early life, socioeconomic confounding, or shrinkage? $\mathcal{f}$ Epidemiol Community Health confounding,
1995;49:5-9. 
14 Hebert PR, Rich-Edwards JW, Manson JE, et al. Height and incidence of cardiovascular disease in male physicians. Circulation 1993;88(part 1):1437-43

15 D'Avanzo B, La Vecchia C, Negri E. Height and the risk of acute myocardial infarction in Italian women. Soc Sci Med 1994;38:193-6.

16 Manson J, Colditz GA, Stampfer MJ. Parity, ponderosity, and the paradox of a weight-preoccupied society. $\mathscr{f} A M A$ 1994;271:1787-90.

17 Pi-Sunyer FX. The fattening of America. FAMA 1994; 272:238-9.

18 Rissanen AM, Heliövaara M, Knekt P, Reunanen A, Aromaa A. Determinants of weight gain and overweight in adult Finns. Eur $\mathcal{F}$ Clin Nutr 1991;45:419-30.

19 Pi-Sunyer FX. Medical hazards of obesity. Ann Intern Med 1993;119:655-60

20 Garrow JS. Should obesity be treated? $B M F$ 1994; 309:654-5.

21 Wooley SC, Garner DM. Dietary treatments for obesity are ineffective $B M F$ 1994:309:655-6.

22 Vandenbroucke JP, Mauritz BJ, de Bruin A, Verheesen JHH, van der Heide-Wessel $C$, van der Heide RM. Weight, smoking, and mortality. $\mathscr{f} A M A$ 1984;252:2859-60.

23 Rissanen A, Knekt P, Heliövaara M, Aromaa A, Reunanen A, Maatela J. Weight and mortality in Finnish women. $\mathcal{f}$ Clin Epidemiol 1991;44:787-95.
24 Stevens J, Keil JE, Rust PF, Tyroler HA, Davis CE, Cazes PC. Body mass index and body girths as predictors of mortality in black and white women. Arch Intern Med 1992;152:1257-62

25 Hoffmans MDAF, Kromhout D, De Lezenne Coulander C The impact of body mass index of 78,61218 -year old Dutch men on 32-year mort

26 Rissanen A, Heliövaara M, Knekt P, Aromaa A, Reunanen A, Maatela J. Weight and mortality in Finnish men. $7 \mathrm{Cl}$ Epidemiol 1989;42:781-9.

27 Wannamethee G, Shaper AG. Body weight and mortality in middle aged British men: impact of smoking. $B M \mathcal{F}$ 1989;299:1497-502.

28 Lee I-M, Manson J, Hennekens CH, Paffenberger RS. Bod weight and mortality: A 27 -year follow-up of middle-aged men. $¥ A M A$ 1993;270:2823-8.

29 Sidney S, Friedman GD, Siegelaub AB. Thinness and mortality. Am f Public Health 1987;77:317-22.

30 Lindstedt K, Tonstad S, Kuzma JW. Body mass index and patterns of mortality among Seventh-day Adventist men. Int 7 Obesity 1991;15:397-406.

31 Andres R, Muller DC, Sorkin JD. Long-term effects of change in body weight on all-cause mortality. Ann Inter Med 1993;119:737-43. 